\title{
Simplified Analytical Method for Optimized Initial Shape Analysis of Self-Anchored Suspension Bridges and Its Verification
}

\author{
Myung-Rag Jung, Dong-Ju Min, and Moon-Young Kim \\ School of Civil and Architecture Engineering, Sungkyunkwan University, 2066 Seobu-ro, Jangan-gu, Suwon-si 16419, Republic of Korea \\ Correspondence should be addressed to Moon-Young Kim; kmye@skku.edu
}

Received 1 September 2015; Revised 2 December 2015; Accepted 3 December 2015

Academic Editor: Zhike Peng

Copyright (C) 2015 Myung-Rag Jung et al. This is an open access article distributed under the Creative Commons Attribution License, which permits unrestricted use, distribution, and reproduction in any medium, provided the original work is properly cited.

A simplified analytical method providing accurate unstrained lengths of all structural elements is proposed to find the optimized initial state of self-anchored suspension bridges under dead loads. For this, equilibrium equations of the main girder and the main cable system are derived and solved by evaluating the self-weights of cable members using unstrained cable lengths and iteratively updating both the horizontal tension component and the vertical profile of the main cable. Furthermore, to demonstrate the validity of the simplified analytical method, the unstrained element length method (ULM) is applied to suspension bridge models based on the unstressed lengths of both cable and frame members calculated from the analytical method. Through numerical examples, it is demonstrated that the proposed analytical method can indeed provide an optimized initial solution by showing that both the simplified method and the nonlinear FE procedure lead to practically identical initial configurations with only localized small bending moment distributions.

\section{Introduction}

It is well known that cables cannot behave as structural members until large tensioning forces are induced. Therefore, in order to design a cable-supported structure economically and efficiently, it is extremely important to determine the optimized initial cable tensions or unstrained lengths so that internal forces such as bending moments can be minimized even though large compressive forces in the frame members are ineluctable under self-weights.

Generally, the analysis process of finding an initial equilibrium state very close to the target configuration of cable structures under full dead loads is known as shape finding, form finding, or initial shape analysis. Until now, nonlinear FE analysis procedures based on the Newton iteration method have been developed for shape finding problems of cable bridges: the trial-and-error method [1], the initial force method [2], the analytical and iteration method [3-5], the target configuration under dead loads (TCUD) related methods [6-8], and the optimization method $[9,10]$. Of these methods, it should be pointed out that the G.TCUD method by Jung et al. [8], which generalizes the TCUD method by Kim and Lee [6], can provide an ideally optimized initial shape well suited to the target configuration of suspension bridges. However, it is somewhat difficult to implement in general-purpose programs because all unstrained lengths are included in the nodal variables, as the additional unknown and the geometrically nonlinear analyses need to be performed based on a tangential stiffness matrix, which is nonsymmetrical.

On the other hand, some analytical methods $[4,7,8]$ in the first stage have been proposed to obtain the trial initial state solution of cable-supported bridges. These schemes are mainly based on a continuous beam model under dead loads virtually supported at anchor points as shown in Figure 1. Particularly, in the case of earth-anchored suspension bridges [8], the hanger tensions, the horizontal tension, and the initial profile of the main cable can be accurately evaluated from the linear elastic analysis of this beam model and balanced conditions at nodal points on the main cable, which leads to 


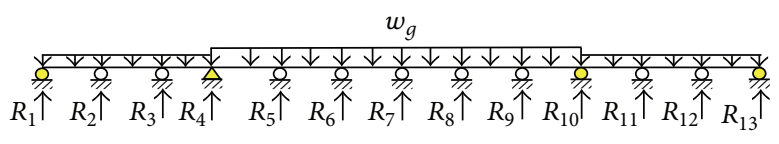

(a) Continuous main girder model subjected to self-weights only: earth-anchored suspension bridge

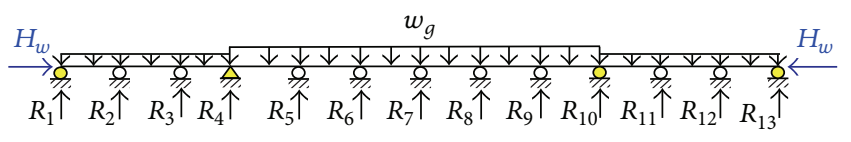

(b) Main girder model under self-weights and uniform compression: selfanchored suspension bridge

FIGURE 1: Continuous girder models having the initial camber in suspension bridges.

a minimized moment distribution of the main girder and the tower.

However, for self-anchored suspension bridges having fabrication cambers, it should be noted that most initial state solutions obtained analytically using these methods fail to find an optimized initial configuration because the globally large bending moments in the main girder can incur owing to the combined action $(P-\Delta$ effect) of the fabrication cambers and the horizontal tension components of the main cable or the stay cables. Thus, it is clear that while these initial solutions using the previous analytical methods are not problematic when simply used as a trial initial state for nonlinear FE analysis, they cannot be directly used as an initial configuration in the preliminary design of selfanchored suspension bridges.

On the other hand, it appears that the analytical calculation method proposed by Wang et al. [5] can provide an optimized initial state solution for self-anchored suspension bridges by iteratively updating the horizontal tension of the main cable. Nonetheless, its mathematical formulation can be complex because the Newton iteration method is fully adopted based on the elastic catenary cable theory, while the self-weights of hangers are neglected. In addition, it should be pointed out that the initial forces of cable and frame elements are used instead of the unstrained lengths in formulating the initial shaping procedure.

In this study, a simplified analytical method providing accurate unstrained lengths of all structural elements is proposed to find the optimized initial state of self-anchored suspension bridges under dead loads. For this, equilibrium equations of the main girder and the main cable system are analytically derived and solved by accurately evaluating the self-weights of cable members using unstrained cable lengths and iteratively updating the horizontal tension component of the main cable. Through numerical examples, it is demonstrated that the proposed analytical method can indeed provide the optimized initial solution by showing that both the simplified method and the nonlinear finite element (FE) procedure (unstrained element length method (ULM)) lead to very similar initial configurations with only localized small bending moment distributions.

\section{A Simplified Analytical Method for Determining the Optimized Initial Shape of Self-Anchored Suspension Bridges}

In Section 2.1, discussion is provided on developing a simplified analytical method, and in the subsequent two sections, simultaneous differential equations and nonlinear equations representing the equilibrium conditions are formulated and solved for the main girder and the main cable system, respectively. In the last section, a simplified analytical procedure is proposed to find the optimized initial configuration of the suspension bridges.

2.1. Initial Shaping Analysis of Suspension Bridges. Ordinarily suspension bridges consist of main girders and towers and main cable systems connecting them. To design these structures economically, not only should the internal forces of the main members due to dead loads be minimized by initial shaping analysis, but also the initial configuration should fit in well with the target configuration. In other words, the horizontal and vertical displacements of the tower and the main girder should be zero or extremely small because the target configuration is given as initial coordinates. Particularly, in the case of self-anchored suspension bridges, bending moments by initial shaping analysis should almost vanish, except for local moments between anchored points, even though large axial forces in the main girders and the towers are inevitably induced due to the transfer of cable tensions.

Based on these observations, the following comments are provided to gain some insight into the mechanical behaviors of suspension bridges under dead load before a simplified analytical method to determine the optimized initial solution of suspension bridges.

Comment 1. It is assumed that the main girder model under dead loads in the case of earth-anchored suspension bridges is virtually supported at the nodal points anchored by hangers so that vertical displacements should not occur at these points except for the fabrication camber (Figure 1(a)).

Clearly this assumption leads to the minimized bending moment distribution of the stiffening girder because it causes only local bending moments due to dead loads between anchored points. Furthermore, reaction forces at the rollersupported anchor points can be directly used in determining the tensions of hanger cables. In other words, no vertical deflections of the main girder should occur at the anchor points in order to determine the optimized hanger tensions of earth-anchored suspension bridges under dead loads. In the literature, this approach is called either the rigid supported continuous beam method, the zero displacement method, or the minimum bending energy method.

Comment 2. For self-anchored suspension bridges having an initial camber, the main girder, which is subjected to both dead loads and large compressive force transferred by the 
main cable, should be supported by rollers at the anchored points (Figure 1(b)).

It should be noted that, in the case of self-anchored suspension bridges with a fabrication camber under dead loads, horizontal tension components of the main cable can induce extremely large negative bending moments in the main girder as the span length is increased. To eliminate these moments and obtain the optimized initial state solution, the tension components of the hanger cables should be suitably decreased in order to exclude these bending moments, except for local moments. This difficulty can be overcome by analyzing the continuous beam subjected to not only the self-weight but also large compression due to the main cable. Because the accurate horizontal tension of the main cable is not known in advance, it should be calculated through the iterative analysis of the main girder linked to the main cable system.

Comment 3. The balance condition of self-weights between the center span and the side spans is not required in the case of suspension bridges because some imbalance can be overcome by suitably changing the initial profile of the main cable system irrespective of whether it is an earth-anchored or self-anchored system.

The main cable system of suspension bridges can be designed so no bending moments occur in the tower by controlling the initial profile of the main cable so that the horizontal tension can remain constant throughout the main cable. This is possible because the main cable and hanger cables of suspension bridges form a cable system so that it can take an optimized configuration in harmony with external forces.

Comment 4. The main cable segments between hanger cables are assumed to be parabolic under self-weight $w L_{o}$ and nodal forces can be decomposed into the nominal tension $T_{\theta}$ and the two vertical reaction components $w L_{o} / 2$ as shown in Figure 2. Particularly, the unstrained (unstressed) length $L_{o}$ of a main cable segment with inclined angle $\theta$ and axial rigidity $E A_{o}$ can be evaluated from the cubic equation of (la) and (1b) when their nominal tension $T_{\theta}$ and the chord length $l$ are given:

$$
T_{\theta}^{3}+\frac{E A_{o}}{L_{o}}\left(L_{o}-l\right) T_{\theta}^{2}-\frac{E A_{o}\left(w L_{o} \cos \theta\right)^{2}}{24}=0 .
$$

Then, Ernst's equivalent elastic modulus is derived by differentiating $T_{\theta}$ with respect to $l$. Consider

$$
\frac{d T_{\theta}}{d l}=\frac{E}{1+\left(\left(w L_{o} \cos \theta\right)^{2} / 12 T_{\theta}^{3}\right) E A_{o}} \frac{A_{o}}{L_{o}} \equiv \frac{E_{\mathrm{eq}} A_{\mathrm{o}}}{L_{o}} .
$$

Essentially, each main cable segment between hangers should be modeled as an elastic catenary cable element. However, a main cable segment can be regarded as an elastic parabolic cable element with sufficient accuracy owing to its small sag and relatively large tension. This means that the main cable segment is assumed to behave as a truss

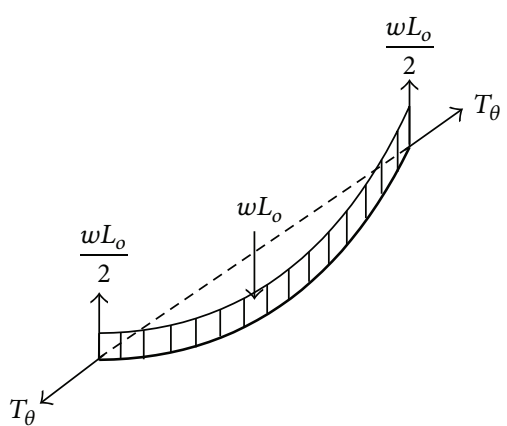

FIGURE 2: Free body diagram of a main cable segment under its selfweight.

element when deriving the force equilibrium conditions at the connection points by hangers, but its unstrained cable length can be accurately evaluated from (1a) and (1b) after the nominal tension and the chord length are determined. Generally, the unstrained cable length of the tensioned cable segments with some small sag is almost the same as the straight chord length, but their self-weight is precisely calculated using $w_{m} L_{o}$ instead of $w_{m} l$.

Comment 5. $x$-coordinates at the anchor points of the main cable and the main girder connected by hangers are fixed in the target configuration of suspension bridges under dead loads so that the hanger cables remain vertical in the initial shaping analysis. In this case, the unstrained length of the hanger cables is evaluated using Hooke's law, (2), and selfweight of hangers is $w_{h} l$. Consider

$$
P=E A \frac{l-L_{o}}{L_{o}} .
$$

Comment 6. The axial deformations of the main girder and the main towers are so small that their effects can be neglected when deriving equilibrium equations. Furthermore, the unstrained lengths of the girder and the tower elements are evaluated using Hooke's law when their axial force $P$ and chord length $l$ are given.

2.2. Continuous Main Girder Subjected to Both Its Weight and Large Compression. Generally, a self-anchored suspension bridge can be separated into a main girder and a main cable system coupled by both the hanger tensions and the horizontal tension component of the main cable as shown in Figure 3. The stiffening girder system subjected to hanger tensions and the compressive force transferred from the main cable are taken into account in this section. According to Comment 2, the girder model with the initial camber is assumed to be roller-supported at the anchorage of hangers to minimize bending moment distributions.

Considering the half girder model where the central hanger is excluded, the total number of girder segments between hanger cables becomes $m+n+2$ when the numbers of hanger cables in the center span and the side span are $2 n+1$ and $m$, respectively. For a typical $i$ th girder segment, the differential equation for its equilibrium state under uniformly 


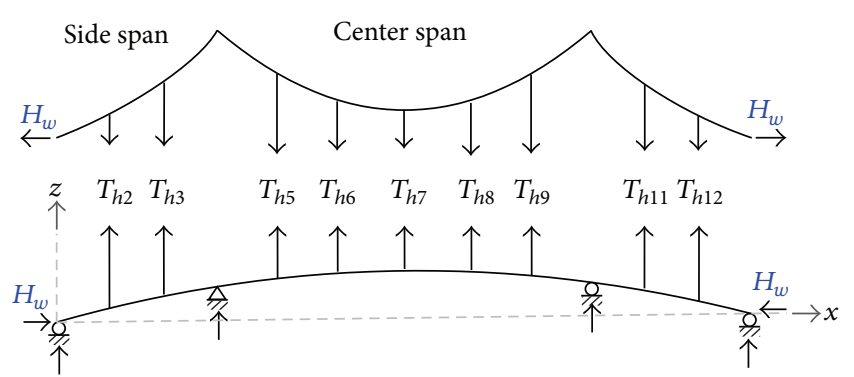

FIGURE 3: Separated main girder and main cable system.

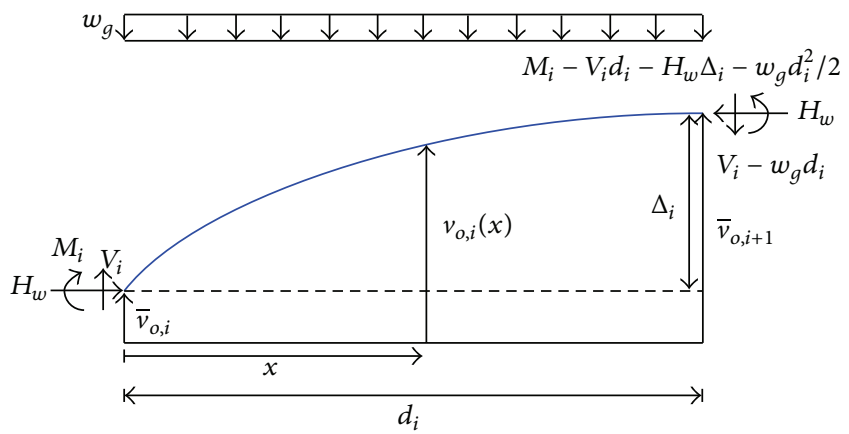

FIGURE 4: Free body diagram of the $i$ th main cable segment.

distributed self-weights $w_{g}$ and large compression $H_{w}$ is derived as follows:

$$
\begin{aligned}
& -E_{g} I_{g}\left(v_{i}+v_{o i}\right)^{\prime \prime}=H_{w} v_{i}-\frac{w_{g} x^{2}}{2}+V_{i} x+M_{i} \\
& \text { for } i=1, m+n+2,
\end{aligned}
$$

where the prime dictates the differentiation with respect to $x$ and the boundary conditions are given as

$$
\begin{gathered}
v_{i}(0)=-v_{o i}(0)=-\bar{v}_{o, i}, \\
v_{i}\left(d_{i}\right)=-v_{o i}\left(d_{i}\right)=-\bar{v}_{o, i+1},
\end{gathered}
$$

with $v_{o i}(x), \bar{v}_{o, i}$ representing the initial camber function of the $i$ th girder segment and the camber at the $i$ th support, respectively, which are positive in the upward direction, $v_{i}(x)$ representing vertical deflection of the girder, positive in the downward direction, $w_{q}, E_{g} I_{q}$ representing self-weight per unit length and flexural rigidity of the girder, respectively, $V_{i}, M_{i}$ representing shear force and bending moment at the left end of the girder segment, respectively, and $d_{i}\left(\equiv x_{i+1}-x_{i}\right)$ representing the segment length. Note that the camber of the girder is usually fabricated to be upward convex due to the drainage problem and the actual displacement of the girder is $v_{i}+v_{o i}$.

From the free body diagram of the $i$ th segment (see Figure 4), the recurrence relations of $V_{i}, M_{i}$, and the internal forces expressed with respect to the reaction forces $R_{i}$ are obtained as follows:

$$
\begin{aligned}
& V_{1}=R_{1} \\
& V_{i}=V_{i-1}-w_{g} d_{i}+R_{i}=\sum_{j=1}^{i} R_{j}-\sum_{j=1}^{i-1} w_{g} d_{j}
\end{aligned}
$$

$$
\text { for } i=2,3, \ldots, m+n+2 \text {, }
$$

$$
\begin{aligned}
M_{1}= & 0 \\
M_{i}= & M_{i-1}-H_{w} \Delta_{i-1}+V_{i-1} d_{i-1}-\frac{w_{g} d_{i-1}^{2}}{2} \\
= & -\sum_{j=1}^{i-1}\left[H \Delta_{j}+\frac{w_{g}}{2} d_{j}^{2}\right] \\
& +\sum_{j=1}^{i-1}\left[\sum_{k=1}^{j} R_{k}-\sum_{k=1}^{j-1} w_{g} d_{k}\right] d_{j}
\end{aligned}
$$

for $i=2,3, \ldots, m+n+2$,

where $\Delta_{i} \equiv \bar{v}_{o, i+1}-\bar{v}_{o, i}$, with $R_{1}, R_{m+2}$ representing reactions at the real supports.

Also, assuming that $v_{o i}(x)=G_{i 0}+G_{i 1} x+G_{i 2} x^{2} / 2+G_{i 3} x^{3} / 6$, (3a) can be rewritten as

$$
\begin{array}{r}
v_{i}^{\prime \prime}+A^{2} v_{i}=B x^{2}-V_{i}^{*} x-M_{i}^{*}-\left(G_{i 2}+G_{i 3} x\right) \\
\text { for } i=1, m+n+2,
\end{array}
$$

$$
\begin{aligned}
A^{2} & =\frac{H_{w}}{E_{g} I_{g}}, \\
B & =\frac{w_{g}}{2 E_{g} I_{g}}, \\
V_{i}^{*} & =\frac{V_{i}}{E_{g} I_{g}}, \\
M_{i}^{*} & =\frac{M_{i}}{E_{g} I_{g}} .
\end{aligned}
$$

As a result, the closed-form solution of (5) is obtained as follows:

$$
\begin{aligned}
& v_{i}(x) \\
& =C_{1 i} \cos (A x)+C_{2 i} \sin (A x) \\
& +\frac{B\left(A^{2} x^{2}-2\right)-A^{2}\left(M_{i}^{*}+V_{i}^{*} x+G_{i 2}+G_{i 3} x\right)}{A^{4}}
\end{aligned}
$$




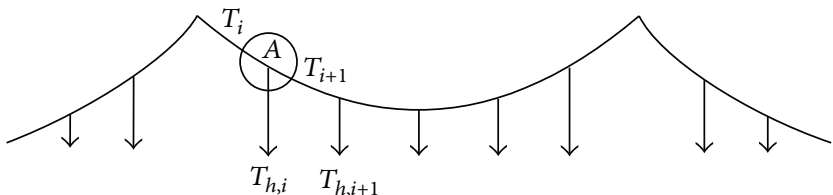

(a) Main cable system

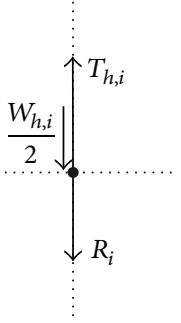

(b) Free body diagram at the anchorage point of hangers

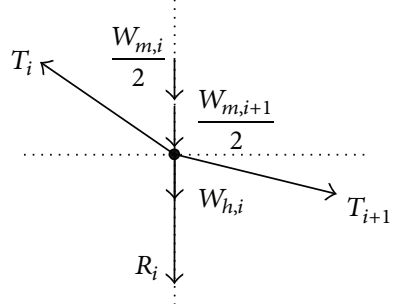

(c) Free body diagram: detail of $A$

FIGURE 5: Main cable system and free body diagrams at the connecting points.

$$
\begin{aligned}
C_{1 i}= & \frac{2 B+A^{2}\left(M_{i}^{*}+G_{i 2}\right)}{A^{4}}-\bar{v}_{o, i} \\
C_{2 i} & \\
= & -\frac{\cos \left(A d_{i}\right)\left(2 B+A^{2}\left(M_{i}^{*}+G_{i 2}\right)\right)}{A^{4} \sin \left(A d_{i}\right)} \\
& -\frac{B\left(A^{2} d_{i}^{2}-2\right)-A^{2}\left(M_{i}^{*}+V_{i}^{*} d_{i}+G_{i 2}+G_{i 3} d_{i}\right)}{A^{4} \sin \left(A d_{i}\right)} \\
& -\frac{\bar{v}_{o, i+1}-\cos \left(A d_{i}\right) \bar{v}_{o, i}}{\sin \left(A d_{i}\right)} .
\end{aligned}
$$

Finally, invoking the continuity conditions at the anchor points and the symmetry conditions at the right end leads to

$$
\begin{aligned}
v_{i}^{\prime}\left(d_{i}\right)+v_{o, i}^{\prime}\left(d_{i}\right) & =v_{i+1}^{\prime}(0)+v_{o, i+1}^{\prime}(0) \\
\qquad \text { for } i=1, m+n+1, & \\
v_{m+n+2}^{\prime}\left(d_{m+n+2}\right) & =0, \\
E_{g} I_{g} v_{m+n+2}^{\prime \prime \prime}\left(d_{m+n+2}\right) & =\frac{R_{m+n+3}}{2} .
\end{aligned}
$$

Clearly, (7) is uniquely solved when $H_{w}$ is given because it is a set of simultaneous linear equations with respect to $R_{i}$ for $i=1, m+n+3$.

\subsection{Main Cable Subjected to Both Cable Weights and Hanger} Tensions. After the reaction forces $R_{i}$ are determined at the supports of the main girder under given $H_{w}$, the main cable system subjected to hanger tensions and its weight are taken into account in order to update the horizontal tension component $H_{w}$ and the vertical profile $z_{i}$ of the main cable. In the present iteration process, it is important to note that self-weights of hangers and main cable segments are evaluated by multiplying the weight per unit length by calculated unstrained cable lengths which are based on the previous profile $z_{i}$ even though the exact unstrained cable lengths should be determined from the converged shape. The detailed procedure to calculate the new horizontal tension $\widehat{H}_{w}$ and the profile $\widehat{z}_{i}$ is as follows.

First, calculate the chord lengths $l_{m, i}$ and $l_{h, i}$ of the $i$ th main cable segment and the $i$ th hanger based on the current nodal coordinate $\left(x_{i}, z_{i}\right)$ of the main cable as

$$
\begin{aligned}
& l_{m, i}=\sqrt{\left(x_{i+1}-x_{i}\right)^{2}+\left(z_{i+1}-z_{i}\right)^{2}}, \\
& l_{h, i}=z_{i}-z_{o i} .
\end{aligned}
$$

Next, determine the unstrained lengths of the main cable segment and the hanger from (1a), (1b), and (2) after the hanger tensions referring to Figure 5(b) are evaluated using (9). Consider

$$
T_{h, i}=R_{i}+\frac{W_{h, i}}{2}
$$

Then, the vertical loads $W_{D i}$ acting at the junctions of the main cable and hangers due to cable weights and the reaction forces $R_{i}$ are evaluated as follows:

$$
W_{D i}=\frac{1}{2}\left(W_{m, i}+W_{m, i+1}\right)+R_{i}+W_{h, i} .
$$

Finally, set up the nodal equilibrium equations of the main cable system by deriving vertical equilibrium equations at the ith node (see Figures 5(a) and 5(c)) as follows:

$$
\begin{aligned}
& \widehat{H}_{w} \frac{\widehat{z}_{i-1}-\widehat{z}_{i}}{d_{i}}-\widehat{H}_{w} \frac{\widehat{z}_{i}-\widehat{z}_{i+1}}{d_{i+1}}=W_{D i} \\
& \quad \text { for } i=2, \ldots, m+1, m+3, \ldots, m+2 n+3,
\end{aligned}
$$

where the above equations represent a set of simultaneous equations with unknown variables equal to the total number of independent equations because $\widehat{H}_{w}$ and $\widehat{z}_{i}$ are unknown variables except for the sag $f\left(=z_{m+n+3}\right)$ at the mid-point of the center span given as a design parameter. It should be noted that the horizontal tension components in the center span and the side span are equal in the initial state solutions, so that the main tower is subjected to no horizontal force.

Consequently, $\widehat{H}_{w}$ and $\widehat{z}_{i}$ of the center span are first evaluated by solving (11) in the center span and $\widehat{z}_{i}$ of the side 
span are then calculated using $\widehat{H}_{w}$ previously determined. The evaluation procedure is as follows:

(a) Define the $m+2 n+1$ unknowns: $z_{i}^{*} \equiv \widehat{H}_{w} \widehat{z}_{i}$ for $i=$ $2, \ldots, m+1, m+3, \ldots, m+2 n+3$.

(b) Because the profiles at the anchorage and the tower saddle $z_{1}, z_{m+2}, z_{m+2 n+4}, z_{2 m+2 n+5}$ are known beforehand, rearrange the following variables using the sag $f$ :

$$
\begin{aligned}
\widehat{H}_{w} z_{j} \equiv \frac{z_{m+n+3}^{*} z_{j}}{f} & \\
& \quad \text { for } j=1, m+2, m+2 n+4,2 m+2 n+5 .
\end{aligned}
$$

(c) Evaluate updated $\widehat{H}_{w}$ and $\widehat{z}_{i}$ in the center span by solving the following linear simultaneous equation:

$$
\begin{aligned}
& -\left(\frac{1}{d_{m+2}}+\frac{1}{d_{m+3}}\right) z_{m+3}^{*}+\frac{1}{d_{m+3}} z_{m+4}^{*} \\
& +\frac{z_{m+2}}{d_{m+2} f} z_{m+n+3}^{*}=W_{D, m+3} \\
& \frac{1}{d_{i}} z_{i-1}^{*}-\left(\frac{1}{d_{i}}+\frac{1}{d_{i+1}}\right) z_{i}^{*}+\frac{1}{d_{i+1}} z_{i+1}^{*}=W_{D i}
\end{aligned}
$$

for $i=m+4, \ldots, m+2 n+2$,

$$
\begin{aligned}
& \frac{1}{d_{m+2 n+1}} z_{m+2 n+2}^{*}-\left(\frac{1}{d_{m+2 n+1}}+\frac{1}{d_{m+2 n+2}}\right) z_{m+2 n+3}^{*} \\
& +\frac{z_{m+2 n+4}}{d_{m+2 n+2} f} z_{m+n+3}^{*}=W_{D, m+2 n+3} .
\end{aligned}
$$

(d) Similarly, update $\widehat{z}_{i}$ in the side span by solving (14) using $\widehat{H}_{w}$ determined in (13):

$$
\begin{aligned}
& -\left(\frac{1}{d_{1}}+\frac{1}{d_{2}}\right) z_{2}^{*}+\frac{1}{d_{2}} z_{3}^{*}+\frac{z_{1}}{d_{1} f} z_{m+n+3}^{*}=W_{D 2}, \\
& \frac{1}{d_{i}} z_{i-1}^{*}-\left(\frac{1}{d_{i}}+\frac{1}{d_{i+1}}\right) z_{i}^{*}+\frac{1}{d_{i+1}} z_{i+1}^{*}=W_{D i}
\end{aligned}
$$$$
\text { for } i=3, \ldots, m \text {, }
$$

$$
\begin{aligned}
& \frac{1}{d_{m}} z_{m}^{*}-\left(\frac{1}{d_{m}}+\frac{1}{d_{m+1}}\right) z_{m+1}^{*}+\frac{z_{m+2}}{d_{m+1} f} z_{m+2}^{*} \\
& \quad=W_{D, m+1}
\end{aligned}
$$

2.4. Simplified Analytical Procedure for Finding an Optimized Initial State of Self-Anchored Suspension Bridges. A simplified analytical procedure for determining the optimized initial state of self-anchored suspension bridges having some camber is presented as follows.

Step 1. Build two structural models separated from the suspension bridge system: the continuous girder model supported by hanger cables and the main cable model subjected to cable weights and hanger tensions (see Figure 3).
Step 2. After the iteration index $k$ is set to be zero, initialize the initial shape $z_{i}^{(o)}$ and the horizontal tension component $H_{w}^{(o)}$ of the main cable under the assumption that it is a parabolic cable under horizontally uniform loads.

Step 3. Begin the iteration process: $k=k+1$.

Step 4. Evaluate the reaction forces $R_{i}^{(k)}$ of the continuous main girder supported at the anchored points subjected to both its self-weight and large compression $H_{w}^{(k-1)}$ using (7).

Step 5. Calculate the chord lengths $l_{m, i}^{(k)}$ and $l_{h, i}^{(k)}$ of both the main cable segment and the hanger based on the current coordinate $\left(x_{i}, z_{i}^{(k-1)}\right)$ and determine the self-weights $W_{m, i}^{(k)}$ and $W_{h, i}^{(k)}$ after calculation of the unstrained cable lengths using (1a), (1b), and (2).

Step 6. Determine the vertical loads $W_{D i}^{(k)}\left(=\left(W_{m, i}^{(k)}+W_{m, i+1}^{(k)}\right) /\right.$ $\left.2+R_{i}^{(k)}+W_{h, i}^{(k)}\right)$ at the junctions of the main cable and hangers due to cable weights and the reaction forces $R_{i}^{(k)}$.

Step 7. Calculate $H_{w}^{(k)}$ and profile $z_{i}^{(k)}$ in the center span by solving (13).

Step 8. Also, calculate profile $z_{i}^{(k)}$ in the side span by solving (14).

Step 9. Check whether or not the horizontal tension $H_{w}^{(k)}$ converges. If it is not converged, go to Step 3 and repeat Steps 3-9. If it is converged, go to Step 10.

Step 10. Establish the nominal tension $T_{m, i}$ of the main cable segment and the hanger tension $T_{h, i}$, and then evaluate the compressive force $P_{w}$ of the tower and the axial forces of the main girder elements having initial cambers using the converged horizontal tension $H_{w}$.

Step 11. Finally determine all the unstrained lengths by using (1a) and (1b) for each cable member and (2) for the vertical hanger cables, main girder elements, and tower elements in order to later utilize them in ULM.

Figure 6 shows a flowchart of the simplified analysis method (SAM) to determine the initial state solution of suspension bridges including all unstrained lengths of cable and frame elements.

Comment 7. In the case of earth-anchored suspension bridges, it should be noted that the reaction forces $R_{i}$ are not varied during the iteration process because the main girder system is not subjected to axial compression.

Comment 8. It is observed that (7) of the main girder system under $H_{w}$ known in the previous iteration step provides $R_{i}$ related to hanger tensions and (13) of the main cable system updates $H_{w}$ and $z_{i}$ based on $R_{i}$ and $z_{i}$ calculated previously. Furthermore, it should be emphasized that (7) and (13) are clearly sets of linear simultaneous equations. 


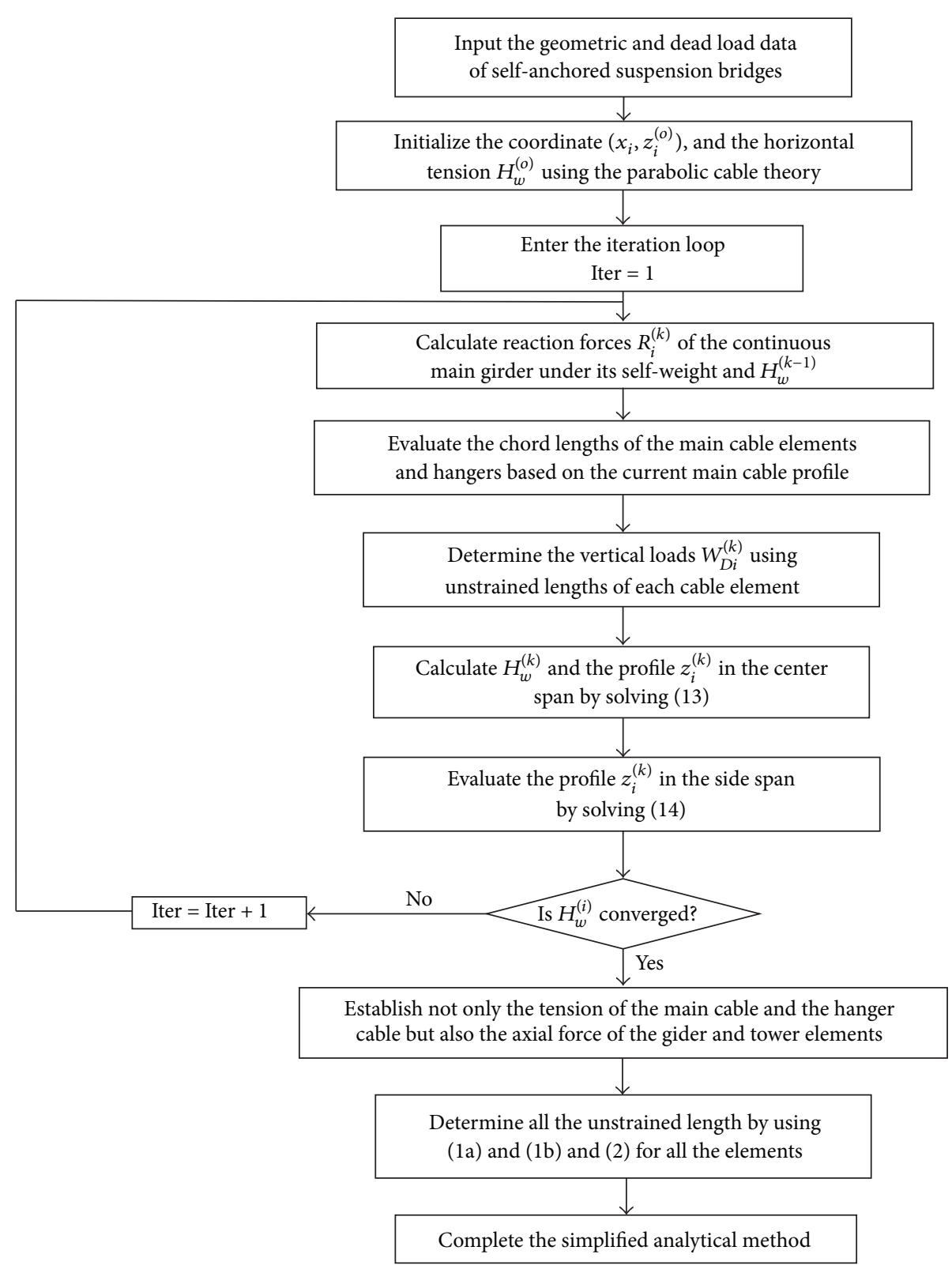

FIGURE 6: Flowchart for the simplified analytical method.

\section{Unstrained Element Length-Based FE Method (ULM)}

A nonlinear analysis method, the unstrained element lengthbased FE method (ULM), is briefly explained in this section for the initial shaping analysis of suspension bridges. The main idea of ULM is the adoption of the conventional Newton iteration method to perform the geometrically nonlinear analysis with the unstrained lengths of both cable and frame elements kept constant in the iteration process. For its successful application, it is extremely important to determine the optimized unstrained element lengths from a suitable scheme.
ULM was first proposed by Jung et al. [8] for the initial shaping nonlinear analysis. ULM basically consists of two stages. In the first stage, accurate unstrained lengths of both cable and frame elements are determined to find an optimized initial configuration of cable bridges. For this purpose, ULM by Jung et al. [8] utilized unstrained lengths of all elements determined from the G.TCUD algorithm [8]. In that method, the unstrained lengths of both the frame element and the cable element are regarded as unknowns and the extended tangential stiffness matrix is derived. As a result, additional geometric constraints equal to the total number of finite elements are imposed to perfectly control the axial and lateral displacements of the main towers and girders. Through this 


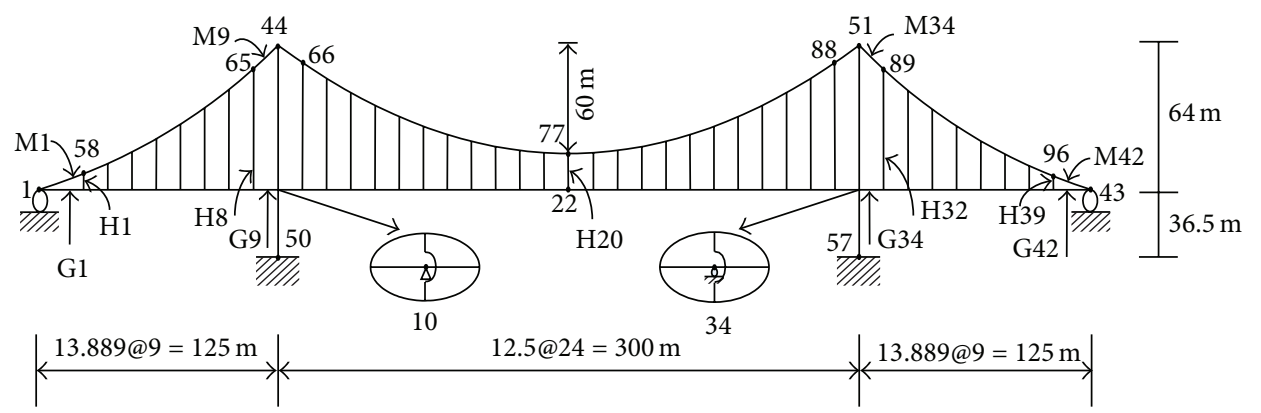

Figure 7: Simplified Yeongjong Bridge model.

process, it was demonstrated that G.TCUD can provide the ideal initial configuration of suspension bridges under dead loads.

On the other hand, in this study, it is emphasized that all the unstrained lengths are determined using the simplified analytical method proposed in the previous section instead of G.TCUD in the first stage. In the second stage of ULM, nonlinear FE analysis based on the Newton iteration method is performed by keeping the unstrained element lengths constant in the subsequent iteration loop as follows:

$$
\begin{aligned}
\mathbf{K}_{t}^{(i-1)} \Delta \mathbf{U}^{(i)} & =\mathbf{W}-\mathbf{F}^{(i-1)} \quad \text { for } i=1,2, \ldots \\
\mathbf{U}^{(i)} & =\mathbf{U}^{(i-1)}+\Delta \mathbf{U}^{(i)} \\
\mathbf{L}_{o}^{(i)} & =\mathbf{L}_{o}^{(i-1)},
\end{aligned}
$$

with $\Delta \mathbf{U}, \mathbf{W}$ representing the incremental nodal displacement and the dead load vector, respectively and $\mathbf{F}^{(i)}$ representing the equivalent internal force vectors due to all member forces. Note that the tangential stiffness matrix $\mathbf{K}_{t}$ is symmetric and vector $\mathbf{L}_{o}$ containing the unstrained lengths of all finite elements remains constant in the iteration process.

In numerical examples of this study, two ULMs, depending on how they are selected, are applied as follows.

(1) $U L M(S)$. The unstrained lengths of both cable and frame elements are determined from the simplified analytical method.

(2) $\operatorname{ULM}(G)$. All the unstrained element lengths are determined from the G.TCUD method.

In FE analysis of suspension bridges using ULM, the main cable segments and hanger cables are modeled using an elastic catenary cable element and truss-cable element, respectively. In addition, an effective frame element which can calculate total deformations and member forces based on the unstrained length should be carefully selected and implemented in modeling the main girder and tower members. In this study, a corotational frame element is chosen based on works by Crisfield [11] and Le et al. [12] and its brief formulation is given by Jung et al. [8].
TABLE 1: Material, geometric, and dead loading data.

\begin{tabular}{lcccc}
\hline Structural member & $E(\mathrm{Gpa})$ & $A\left(\mathrm{~m}^{2}\right)$ & $I\left(\mathrm{~m}^{4}\right)$ & $w(\mathrm{kN} / \mathrm{m})$ \\
\hline Main cable & 196.20 & 0.258 & - & 29.74 \\
Hanger & 137.4 & 0.034 & - & 3.92 \\
Main girder & 206.01 & 1.363 & 217.386 & 445.18 \\
Tower $(-36.5-0 \mathrm{~m})$ & 206.01 & 1.782 & 7.9474 & 274.46 \\
Tower $(0-64 \mathrm{~m})$ & 206.01 & 1.312 & 3.4362 & 202.08 \\
\hline
\end{tabular}

\section{Numerical Examples}

In this section, in order to demonstrate the efficiency and effectiveness of the proposed SAM and the corresponding $\mathrm{ULM}(\mathrm{S})$, the initial state solutions of two self-anchored suspension bridge models are provided and compared with those by G.TCUD and ULM $(G)$. Because all numerical results and figures by G.TCUD and $\operatorname{ULM}(\mathrm{G})$ in the examples are generated or cited from the procedure presented in [8], speech marks are used for their identification.

4.1. Example 1: Simplified Self-Anchored Yeongjong Bridge Model. Figure 7 shows a simplified self-anchored suspension bridge model of Yeongjong Bridge having a center span of $300 \mathrm{~m}$ with sag of $60 \mathrm{~m}$ and side spans of $125 \mathrm{~m}$. The main cable profile is projected in the vertical plane of the bridge and the stiffening truss is modeled as an equivalent girder having a fabrication camber which is linear $\left(v_{o}=0.015 x\right)$ along the side spans and parabolic $\left(v_{o}=-x^{2} / 22,500+11 x / 450-35 / 72\right)$ along the center span. In FE modeling by ULM, the main cable segments and hangers are modeled using 42 and 39 $(=8+23+8)$ elastic catenary cable elements, respectively. Each segment of the main girder separated by two adjacent hangers is modeled using four frame elements. Table 1 summarizes the material, geometric, and dead loading data.

Tables 2 and 3 show the initial coordinates and displacement increments at the nodal point on the main cable and the main girder, respectively, using the shape-finding analysis methods in which " $\Delta$ " refers to the increments relative to the nodal coordinate values (the second and the third columns of Tables 2 and 3) of the initial solution converged by G.TCUD [6]. Particularly, the third column of Table 3 denotes nodal coordinates due to vertical cambers which are assumed to be linear in the side span and parabolic in the center span. 
TABLE 2: Nodal coordinates and displacements at points on the main cable obtained by G.TCUD, SAM, and ULMs.

\begin{tabular}{|c|c|c|c|c|c|c|c|c|c|}
\hline $\begin{array}{l}\text { Node } \\
\text { number }\end{array}$ & $\begin{array}{c}X(\mathrm{~m}) \\
\text { G.TCUD } \\
{[8]}\end{array}$ & $\begin{array}{c}Z(\mathrm{~m}) \\
\text { G.TCUD } \\
{[8]}\end{array}$ & $\begin{array}{c}\Delta X \\
(\mathrm{~mm}) \\
\mathrm{ULM}(\mathrm{G}) \\
{[8]}\end{array}$ & $\begin{array}{c}\Delta Z(\mathrm{~mm}) \\
\mathrm{ULM}(\mathrm{G}) \\
{[8]}\end{array}$ & $\begin{array}{c}\Delta X \\
(\mathrm{~mm}) \\
\text { SAM }\end{array}$ & $\begin{array}{c}\Delta Z(\mathrm{~mm}) \\
\mathrm{SAM}\end{array}$ & $\begin{array}{c}\Delta X \\
(\mathrm{~mm}) \\
\mathrm{ULM}(\mathrm{S})\end{array}$ & $\begin{array}{c}\Delta Z(\mathrm{~mm}) \\
\mathrm{ULM}(\mathrm{S})\end{array}$ & Remarks \\
\hline 1 & 0.000 & 0.000 & 0.0 & 0.0 & 0.0 & 0.0 & 0.0 & 0.0 & \multirow{3}{*}{ Anchor point } \\
\hline 60 & 41.667 & 11.943 & 0.0 & 0.0 & 0.0 & 0.3 & 0.0 & 0.3 & \\
\hline 63 & 83.333 & 33.245 & 0.0 & 0.0 & 0.0 & 0.4 & -0.1 & 0.4 & \\
\hline 44 & 125.000 & 64.000 & 0.0 & 0.0 & 0.0 & 0.0 & 0.0 & 0.0 & \multirow{4}{*}{ Tower saddle } \\
\hline 68 & 162.500 & 37.611 & 0.0 & 0.0 & 0.0 & 0.4 & 0.1 & 0.4 & \\
\hline 71 & 200.000 & 18.892 & 0.0 & 0.0 & 0.0 & 0.3 & 0.1 & 0.2 & \\
\hline 74 & 237.500 & 7.716 & 0.0 & 0.0 & 0.0 & 0.1 & 0.0 & 0.0 & \\
\hline 77 & 275.000 & 4.000 & 0.0 & 0.0 & 0.0 & 0.0 & 0.0 & -0.1 & \multirow{4}{*}{ Sag point } \\
\hline 80 & 312.500 & 7.716 & 0.0 & 0.0 & 0.0 & 0.1 & 0.0 & 0.0 & \\
\hline 83 & 350.000 & 18.892 & 0.0 & 0.0 & 0.0 & 0.3 & -0.1 & 0.2 & \\
\hline 86 & 387.500 & 37.611 & 0.0 & 0.0 & 0.0 & 0.4 & -0.1 & 0.4 & \\
\hline 51 & 425.000 & 64.000 & 0.0 & 0.0 & 0.0 & 0.0 & 0.0 & 0.0 & \multirow{3}{*}{ Tower saddle } \\
\hline 91 & 466.667 & 33.245 & 0.0 & 0.0 & 0.0 & 0.4 & 0.1 & 0.4 & \\
\hline 94 & 508.333 & 11.943 & 0.0 & 0.0 & 0.0 & 0.3 & 0.0 & 0.3 & \\
\hline 43 & 550.000 & 0.000 & 0.0 & 0.0 & 0.0 & 0.0 & 0.0 & 0.0 & Anchor point \\
\hline
\end{tabular}

TABLE 3: Nodal coordinates and displacements at points on the main girder obtained by ULM(G) and ULM(S).

\begin{tabular}{|c|c|c|c|c|c|c|c|}
\hline $\begin{array}{l}\text { Node } \\
\text { number }\end{array}$ & $\begin{array}{c}X(\mathrm{~m}) \\
\text { G.TCUD } \\
{[8]}\end{array}$ & $\begin{array}{c}Z(\mathrm{~m}) \\
\text { G.TCUD } \\
{[8]}\end{array}$ & $\begin{array}{c}X(\mathrm{~mm}) \\
\mathrm{ULM}(\mathrm{G}) \\
{[8]}\end{array}$ & $\begin{array}{c}\Delta Z(\mathrm{~mm}) \\
\mathrm{ULM}(\mathrm{G}) \\
{[8]}\end{array}$ & $\begin{array}{c}\Delta X(\mathrm{~mm}) \\
\operatorname{ULM}(\mathrm{S})\end{array}$ & $\begin{array}{c}\Delta Z(\mathrm{~mm}) \\
\operatorname{ULM}(\mathrm{S})\end{array}$ & Remarks \\
\hline 1 & 0.000 & 0.000 & 0.0 & 0.0 & 0.0 & 0.0 & \multirow{3}{*}{ Anchor point } \\
\hline 4 & 41.667 & 0.625 & 0.0 & 0.0 & 0.0 & 0.0 & \\
\hline 7 & 83.333 & 1.250 & 0.0 & 0.0 & 0.0 & 0.0 & \\
\hline 10 & 125.000 & 1.875 & 0.0 & 0.0 & 0.0 & 0.0 & \multirow{4}{*}{ Left tower } \\
\hline 13 & 162.500 & 2.313 & 0.0 & 0.0 & 0.0 & 0.0 & \\
\hline 16 & 200.000 & 2.625 & 0.0 & 0.0 & 0.0 & 0.0 & \\
\hline 19 & 237.500 & 2.813 & 0.0 & 0.0 & 0.0 & -0.1 & \\
\hline 22 & 275.000 & 2.875 & 0.0 & 0.0 & 0.0 & -0.1 & \multirow{4}{*}{ Sag point } \\
\hline 25 & 312.500 & 2.813 & 0.0 & 0.0 & 0.0 & -0.1 & \\
\hline 28 & 350.000 & 2.625 & 0.0 & 0.0 & 0.0 & 0.0 & \\
\hline 31 & 387.500 & 2.313 & 0.0 & 0.0 & 0.0 & 0.0 & \\
\hline 34 & 425.000 & 1.875 & 0.0 & 0.0 & 0.0 & 0.0 & \multirow{3}{*}{ Right tower } \\
\hline 37 & 466.667 & 1.250 & 0.0 & 0.0 & 0.0 & 0.0 & \\
\hline 40 & 508.333 & 0.625 & 0.0 & 0.0 & 0.0 & 0.0 & \\
\hline 43 & 550.000 & 0.000 & 0.0 & 0.0 & 0.0 & 0.0 & Anchor point \\
\hline
\end{tabular}

In addition, Table 4 designates the unstrained cable lengths obtained by SAM and G.TCUD and their differences. It is noted that the unstrained lengths of all cable and frame elements used in $\operatorname{ULM}(\mathrm{S})$ and $\operatorname{ULM}(\mathrm{G})$ are identical to those in SAM and G.TCUD, respectively.

First, it is observed that the initial shape of the main cable and the main girder by $\operatorname{ULM}(G)$ is the same as that by G.TCUD from the fourth and the fifth columns in Tables 2 and 3. This demonstrates that G.TCUD and the corresponding $\operatorname{ULM}(\mathrm{G})$ indeed provide an ideally optimized initial configuration of self-anchored suspension bridges, which is an important conclusion made by Kim and Lee [6]. Second, the initial state solution by SAM is identical to that by G.TCUD from the seventh column in Table 2 and the fourth column in Table 4. Ed: highlight-colloquial. You can use "... in the end..." or "...finally..." but these are not needed here. Furthermore, it is observed that the initial solutions obtained by $\operatorname{ULM}(\mathrm{S})$ in Tables 2 and 3 closely 
TABLE 4: Unstrained lengths of main cable segments and hanger cables by SAM and G.TCUD.

\begin{tabular}{|c|c|c|c|c|}
\hline Cable number & $\begin{array}{c}L_{o}(\mathrm{~m}) \text { by } \\
\text { SAM } \\
(1)\end{array}$ & $\begin{array}{c}L_{o}(\mathrm{~m}) \text { by } \\
\text { G.TCUD } \\
{[8]} \\
(2)\end{array}$ & $\begin{array}{c}(2)-(1) \\
(\mathrm{mm})\end{array}$ & Remarks \\
\hline M1 & 14.160 & 14.160 & -0.3 & Side span \\
\hline M4 & 15.126 & 15.126 & 0.2 & Side span \\
\hline M7 & 16.619 & 16.619 & -0.2 & Side span \\
\hline M10 & 15.758 & 15.758 & 0.3 & Center span \\
\hline M13 & 14.339 & 14.339 & 0.4 & Center span \\
\hline M16 & 13.280 & 13.280 & 0.4 & Center span \\
\hline M19 & 12.647 & 12.647 & -0.1 & Center span \\
\hline M22 & 12.485 & 12.485 & -0.1 & Center span \\
\hline M25 & 12.807 & 12.807 & 0.5 & Center span \\
\hline M28 & 13.589 & 13.589 & -0.1 & Center span \\
\hline M31 & 14.776 & 14.776 & 0.2 & Center span \\
\hline M34 & 17.878 & 17.878 & 0.3 & Side span \\
\hline M37 & 16.066 & 16.066 & -0.3 & Side span \\
\hline M40 & 14.743 & 14.743 & -0.4 & Side span \\
\hline $\mathrm{H} 1$ & 2.622 & 2.622 & 0.2 & Side span \\
\hline $\mathrm{H} 4$ & 17.037 & 17.037 & -0.5 & Side span \\
\hline $\mathrm{H} 7$ & 40.860 & 40.860 & -0.2 & Side span \\
\hline H10 & 43.423 & 43.422 & -0.5 & Center span \\
\hline H13 & 21.914 & 21.913 & -0.6 & Center span \\
\hline H16 & 8.074 & 8.073 & -0.6 & Center span \\
\hline H19 & 1.803 & 1.803 & -0.1 & Center span \\
\hline $\mathrm{H} 22$ & 3.056 & 3.056 & 0.0 & Center span \\
\hline $\mathrm{H} 25$ & 11.842 & 11.842 & -0.2 & Center span \\
\hline $\mathrm{H} 28$ & 28.225 & 28.225 & -0.4 & Center span \\
\hline H31 & 52.326 & 52.326 & -0.1 & Center span \\
\hline $\mathrm{H} 34$ & 31.860 & 31.859 & -0.6 & Side span \\
\hline $\mathrm{H} 37$ & 11.197 & 11.197 & -0.2 & Side span \\
\hline H39 & 2.622 & 2.622 & 0.2 & Side span \\
\hline
\end{tabular}

agree with those by G.TCUD, which means that SAM can give an optimized initial shape by simple calculation because $\mathrm{ULM}(\mathrm{S})$ is based on the unstrained lengths calculated from SAM. Third, it is perceived that horizontal displacements $\Delta X$ and vertical displacements $\Delta Y$ by both $\operatorname{ULM}(\mathrm{G})$ and $\mathrm{ULM}(\mathrm{S})$ nearly vanish at the connection points of the main cable, at the top of the towers and hangers, and at the anchored points of the main girder. This implies that the use of both ULMs provides an ideal initial shape conforming very well to the required target configuration of self-anchored suspension bridges. Finally, it is surprisingly observed from Tables 2-4 that the results analyzed by ULM(G) and ULM(S) are almost identical to those by G.TCUD, even though any additional constraints in ULM are not enforced, except for the conventional geometric boundary condition.

On the other hand, Figures 8 and 9 show the bending moment diagram of the main girder with fabrication cambers and tensions of hangers along the main girder determined

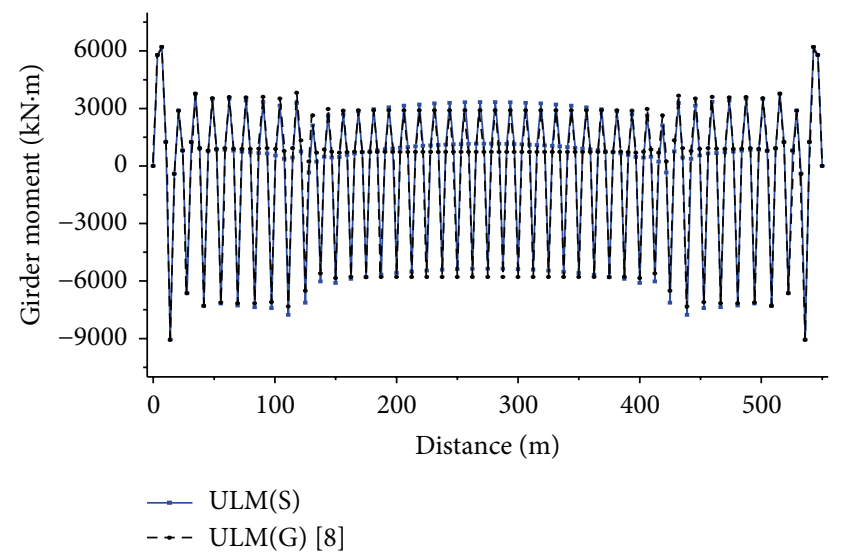

FIGURE 8: Bending moment diagram of the main girder in the selfanchored suspension bridge.

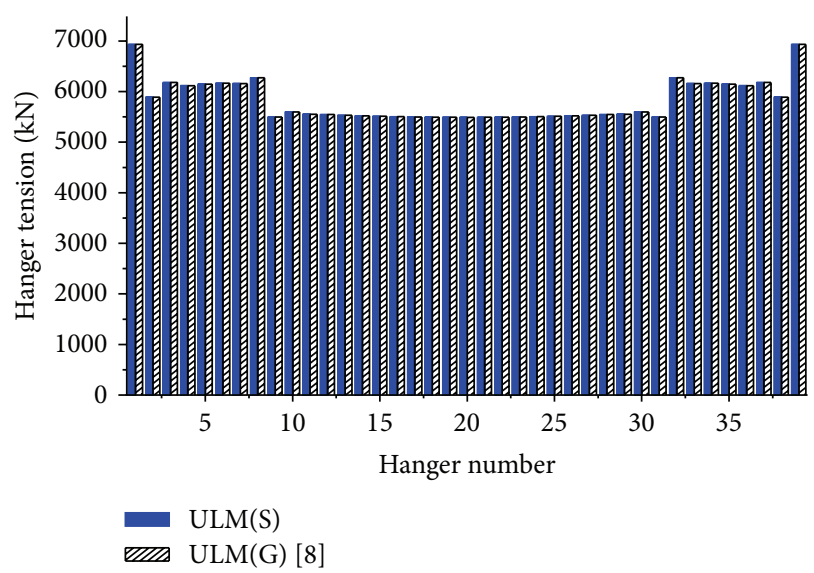

FIGURE 9: Distribution of hanger tensions in the self-anchored suspension bridge.

by two ULMs, respectively. In addition, Table 5 sums up the maximum internal forces and displacements of the main cable, the girder, and towers analyzed by initial shaping analysis methods. It is observed in Figure 8 and Table 5 that the bending moment diagrams of the main girder with cambers obtained by the two ULMs are very similar to that of the continuous beam under dead loads supported at the anchor points and that the maximum bending moments of the girder obtained by the two methods are in exact agreement. In addition, it is observed that the distributions of hanger tensions by the two ULMs show good agreement.

4.2. Example 2: Self-Anchored Suspension Bridge Model Having a Long Center Span of $1200 \mathrm{~m}$. Generally, the span length of self-anchored suspension bridges is very restricted because the main girder is subjected to extremely large compression with the increase of the span length. In this subsection, a virtual self-anchored suspension bridge having an extremely long span length is taken into account. Figure 10 shows the suspension bridge model having an extremely long center span of $1200 \mathrm{~m}$ with sag of $150 \mathrm{~m}$ and side spans of $500 \mathrm{~m}$. The main tower is $175 \mathrm{~m}$ above the girder level. The main 
TABLE 5: Maximum internal forces and displacements in main members of Example 1.

\begin{tabular}{|c|c|c|c|c|}
\hline & SAM & $\mathrm{ULM}(\mathrm{S})$ & G.TCUD [8] & $\mathrm{ULM}(\mathrm{G})[8]$ \\
\hline Horizontal tension component of the main cable $(\mathrm{kN})$ & $88,807.2$ & $88,807.1$ & $88,824.2$ & $88,824.2$ \\
\hline Max. tension of the hanger cable $(\mathrm{kN})$ & $6,932.5$ & $6,931.3$ & $6,932.5$ & $6,932.5$ \\
\hline Max. compressive force of the tower $(\mathrm{kN})$ & $-140,967.7$ & $-141,464.9$ & $-141,498.1$ & $-141,498.1$ \\
\hline Max. positive moment of the main girder $(\mathrm{kN} \cdot \mathrm{m})$ & $6,202.6$ & $6,204.8$ & $6,198.8$ & $6,198.8$ \\
\hline Max. negative moment of the main girder $(\mathrm{kN} \cdot \mathrm{m})$ & $-9,067.5$ & $-9,063.6$ & $-9,075.6$ & $-9,075.6$ \\
\hline Max. bending moment of the tower $(\mathrm{kN} \cdot \mathrm{m})$ & 0.0 & 6.2 & 0.0 & 0.0 \\
\hline Unstrained length of the entire main cable (m) & 612.504 & 612.504 & 612.505 & 612.505 \\
\hline Horizontal displacement at the top of the tower $(\mathrm{mm})$ & 0.0 & 0.0 & 0.0 & 0.0 \\
\hline Vertical displacement at the top of the tower $(\mathrm{mm})$ & 0.0 & 0.0 & 0.0 & 0.0 \\
\hline Axial shortening of the whole main girder $(\mathrm{mm})$ & 0.0 & 0.0 & 0.0 & 0.0 \\
\hline Max. vertical displacement of the main girder $(\mathrm{mm})$ & 0.0 & 0.1 & 0.0 & 0.0 \\
\hline
\end{tabular}

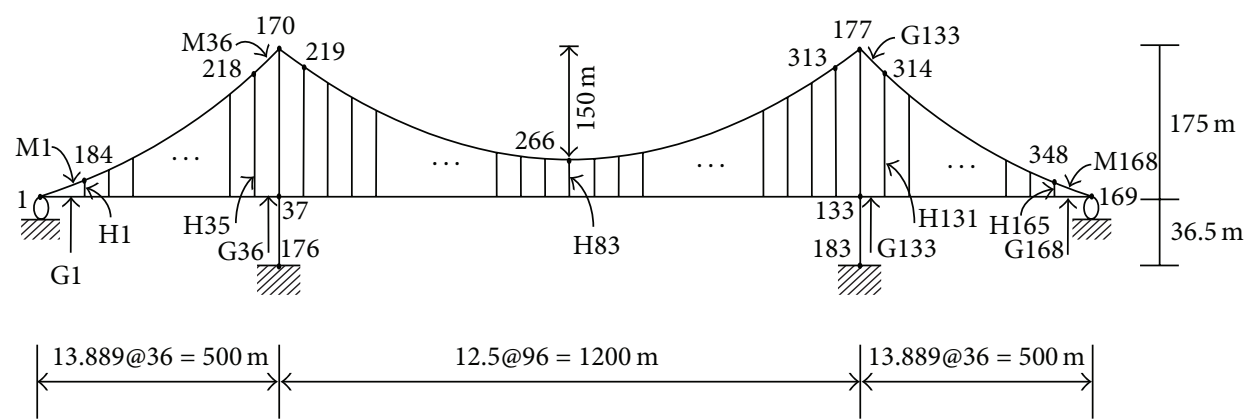

FIGURE 10: Self-anchored suspension bridge having a center span of $1200 \mathrm{~m}$.

cable segments and hangers are modeled using 168 and 165 $(=35+95+35)$ elastic catenary cable elements, respectively. Each girder segment between the two hangers is modeled by four frame elements. The material and geometric data of the bridge model are the same as those of Table 1, except for the tower height. Also, the vertical camber of the main girder is linear $\left(v_{o}=0.015 x\right)$ along the side spans and parabolic $\left(v_{o}=-x^{2} / 90,000+11 x / 450-35 / 18\right)$ along the center span.

Similar to Tables 2 and 3, Tables 6 and 7 show the initial coordinates and displacement increments at the nodal point on the main cable and the main girder, respectively. In addition, Table 8 displays the unstrained cable lengths obtained by SAM and G.TCUD.

First, the initial shape of the main cable and the main girder obtained by $\operatorname{ULM}(\mathrm{G})$ is exactly the same as that obtained by G.TCUD from the fourth and the fifth columns in Tables 6 and 7, which shows that G.TCUD and the corresponding $\operatorname{ULM}(\mathrm{G})$ enable the provision of an ideal initial state of extremely long self-anchored suspension bridges. Second, the initial state solution obtained by SAM is identical to that obtained by G.TCUD. Moreover, the initial solutions obtained by ULM(S) in Tables 6 and 7 very closely agree with those obtained by G.TCUD, which demonstrates that SAM can give an optimized initial solution. Third, $\Delta X$ and $\Delta Y$ by both $\operatorname{ULM}(\mathrm{G})$ and $\operatorname{ULM}(\mathrm{S})$ vanish at the connection points of the main cable and the anchored points of the girder, which indicates that the two ULMs provide an ideal initial state conforming very well to the target configuration of suspension bridges.

Figures 11 and 12 display the bending moment diagram of the main girder and distributions of hanger tensions along the main girder determined by the two ULMs, respectively. Table 9 sums up the maximum internal forces and displacements of the main cable, the girder, and towers by initial shaping analysis. It is again observed that the bending moment diagrams of the girder obtained by the two ULMs are very similar to that of the continuous beam supported at the anchor points and that the maximum bending moments of the girder obtained by the two methods are in exact agreement. Also, the distributions of hanger tensions obtained by the two ULMs show good agreement.

\section{Conclusions}

A simplified analytical method (SAM) was proposed to determine the optimized initial configuration of self-anchored suspension bridges under dead loads. The ULM(S) based on unstrained element lengths by SAM was applied to demonstrate its validity and efficiency. The following concluding comments are made based on the numerical results of suspension bridge examples obtained by both the SAM and the $\operatorname{ULM}(\mathrm{S})$. 
TABLE 6: Nodal coordinates and displacements at points on the main cable obtained by G.TCUD, SAM, and ULMs.

\begin{tabular}{|c|c|c|c|c|c|c|c|c|c|}
\hline $\begin{array}{l}\text { Node } \\
\text { number }\end{array}$ & $\begin{array}{c}X(\mathrm{~m}) \\
\text { G.TCUD } \\
{[8]}\end{array}$ & $\begin{array}{c}Z(\mathrm{~m}) \\
\text { G.TCUD } \\
{[8]}\end{array}$ & $\begin{array}{c}\Delta X(\mathrm{~mm}) \\
\mathrm{ULM}(\mathrm{G}) \\
{[8]}\end{array}$ & $\begin{array}{c}\Delta Z(\mathrm{~mm}) \\
\mathrm{ULM}(\mathrm{G}) \\
{[8]}\end{array}$ & $\begin{array}{c}\Delta X(\mathrm{~mm}) \\
\quad \text { SAM }\end{array}$ & $\begin{array}{c}\Delta Z(\mathrm{~mm}) \\
\mathrm{SAM}\end{array}$ & $\begin{array}{c}\Delta X(\mathrm{~mm}) \\
\operatorname{ULM}(\mathrm{S})\end{array}$ & $\begin{array}{c}\Delta Z(\mathrm{~mm}) \\
\operatorname{ULM}(\mathrm{S})\end{array}$ & Remarks \\
\hline 1 & 0.000 & 0.000 & 0.0 & 0.0 & 0.0 & 0.0 & 0.0 & 0.0 & \multirow{4}{*}{ Anchor point } \\
\hline 192 & 125.0 & 23.589 & 0.0 & 0.0 & 0.0 & 0.0 & 0.0 & 0.0 & \\
\hline 201 & 250.0 & 60.410 & 0.0 & 0.0 & 0.0 & 0.0 & 0.0 & 0.1 & \\
\hline 210 & 375.0 & 110.744 & 0.0 & 0.0 & 0.0 & -0.1 & 0.0 & 0.0 & \\
\hline 170 & 500.0 & 175.000 & 0.0 & 0.0 & 0.0 & 0.0 & 0.0 & 0.0 & \multirow{6}{*}{ Tower saddle } \\
\hline 226 & 600.0 & 128.592 & 0.0 & 0.0 & 0.0 & 0.1 & 0.2 & -0.1 & \\
\hline 234 & 700.0 & 90.998 & 0.0 & 0.0 & 0.0 & 0.0 & 0.1 & -0.4 & \\
\hline 242 & 800.0 & 61.993 & 0.0 & 0.0 & 0.0 & 0.0 & 0.1 & -0.7 & \\
\hline 250 & 900.0 & 41.400 & 0.0 & 0.0 & 0.0 & 0.0 & 0.0 & -0.9 & \\
\hline 258 & 1000.0 & 29.094 & 0.0 & 0.0 & 0.0 & 0.0 & 0.0 & -1.0 & \\
\hline 266 & 1100.0 & 25.000 & 0.0 & 0.0 & 0.0 & 0.0 & 0.0 & -1.0 & \multirow{6}{*}{ Sag point } \\
\hline 274 & 1200.0 & 29.094 & 0.0 & 0.0 & 0.0 & 0.0 & 0.0 & -0.9 & \\
\hline 282 & 1300.0 & 41.400 & 0.0 & 0.0 & 0.0 & 0.1 & 0.0 & -0.8 & \\
\hline 290 & 1400.0 & 61.993 & 0.0 & 0.0 & 0.0 & 0.1 & -0.1 & -0.6 & \\
\hline 298 & 1500.0 & 90.998 & 0.0 & 0.0 & 0.0 & 0.1 & -0.1 & -0.3 & \\
\hline 306 & 1600.0 & 128.592 & 0.0 & 0.0 & 0.0 & 0.1 & -0.2 & -0.1 & \\
\hline 177 & 1700.0 & 175.000 & 0.0 & 0.0 & 0.0 & 0.0 & 0.0 & 0.0 & \multirow{4}{*}{ Tower saddle } \\
\hline 322 & 1825.0 & 110.744 & 0.0 & 0.0 & 0.0 & -0.1 & 0.1 & 0.0 & \\
\hline 331 & 1950.0 & 60.410 & 0.0 & 0.0 & 0.0 & -0.1 & 0.1 & 0.0 & \\
\hline 340 & 2075.0 & 23.589 & 0.0 & 0.0 & 0.0 & -0.1 & 0.0 & 0.0 & \\
\hline 169 & 2200.0 & 0 & 0.0 & 0.0 & 0.0 & 0.0 & 0.0 & 0.0 & Anchor point \\
\hline
\end{tabular}

TABLE 7: Nodal coordinates and displacements at points on the main girder obtained by ULM(G) and ULM(S).

\begin{tabular}{|c|c|c|c|c|c|c|c|}
\hline $\begin{array}{l}\text { Node } \\
\text { number }\end{array}$ & $\begin{array}{c}X(\mathrm{~m}) \\
\text { coordinate }\end{array}$ & $\begin{array}{c}Z(\mathrm{~m}) \\
\text { coordinate }\end{array}$ & $\begin{array}{l}\Delta X(\mathrm{~mm}) \text { by } \\
\operatorname{ULM}(\mathrm{G})[8]\end{array}$ & $\begin{array}{l}\Delta Z(\mathrm{~mm}) \text { by } \\
\operatorname{ULM}(\mathrm{G})[8]\end{array}$ & $\begin{array}{c}\Delta X(\mathrm{~mm}) \text { by } \\
\operatorname{ULM}(\mathrm{S})\end{array}$ & $\begin{array}{c}\Delta Z(\mathrm{~mm}) \text { by } \\
\mathrm{ULM}(\mathrm{S})\end{array}$ & Remarks \\
\hline 1 & 0.000 & 0.000 & 0.0 & 0.0 & 0.0 & 0.0 & \multirow{4}{*}{ Anchor point } \\
\hline 10 & 125.0 & 1.875 & 0.0 & 0.0 & 0.0 & 0.1 & \\
\hline 19 & 250.0 & 3.750 & 0.0 & 0.0 & 0.0 & 0.1 & \\
\hline 28 & 375.0 & 5.625 & 0.0 & 0.0 & 0.0 & 0.1 & \\
\hline 37 & 500.0 & 7.500 & 0.0 & 0.0 & 0.0 & 0.0 & \multirow{6}{*}{ Left tower } \\
\hline 45 & 600.0 & 8.722 & 0.0 & 0.0 & 0.0 & -0.2 & \\
\hline 53 & 700.0 & 9.722 & 0.0 & 0.0 & 0.0 & -0.4 & \\
\hline 61 & 800.0 & 10.500 & 0.0 & 0.0 & 0.0 & -0.7 & \\
\hline 69 & 900.0 & 11.056 & 0.0 & 0.0 & 0.0 & -0.9 & \\
\hline 77 & 1000.0 & 11.389 & 0.0 & 0.0 & 0.0 & -1.0 & \\
\hline 85 & 1100.0 & 11.500 & 0.0 & 0.0 & 0.0 & -1.0 & \multirow{6}{*}{ Sag point } \\
\hline 93 & 1200.0 & 11.389 & 0.0 & 0.0 & 0.0 & -1.0 & \\
\hline 101 & 1300.0 & 11.056 & 0.0 & 0.0 & 0.0 & -0.9 & \\
\hline 109 & 1400.0 & 10.500 & 0.0 & 0.0 & 0.0 & -0.7 & \\
\hline 117 & 1500.0 & 9.722 & 0.0 & 0.0 & 0.0 & -0.4 & \\
\hline 125 & 1600.0 & 8.722 & 0.0 & 0.0 & 0.0 & -0.2 & \\
\hline 133 & 1700.0 & 7.500 & 0.0 & 0.0 & 0.0 & 0.0 & \multirow{4}{*}{ Right tower } \\
\hline 142 & 1825.0 & 5.625 & 0.0 & 0.0 & 0.0 & 0.1 & \\
\hline 151 & 1950.0 & 3.750 & 0.0 & 0.0 & 0.0 & 0.1 & \\
\hline 160 & 2075.0 & 1.875 & 0.0 & 0.0 & 0.0 & 0.1 & \\
\hline 169 & 2200.0 & 0.000 & 0.0 & 0.0 & 0.0 & 0.0 & Anchor point \\
\hline
\end{tabular}


TABLE 8: Unstrained lengths of main cable segments and hanger cables by SAM and G.TCUD.

\begin{tabular}{|c|c|c|c|c|}
\hline $\begin{array}{l}\text { Cable } \\
\text { number }\end{array}$ & $\begin{array}{c}L_{o}(\mathrm{~m}) \text { by } \\
\text { SAM } \\
(1)\end{array}$ & $\begin{array}{c}L_{o}(\mathrm{~m}) \text { by } \\
\text { G.TCUD } \\
{[8]} \\
(2)\end{array}$ & $\begin{array}{c}(2)-(1) \\
(\mathrm{mm})\end{array}$ & Remarks \\
\hline M1 & 13.869 & 13.869 & 0.0 & Side span \\
\hline M13 & 14.266 & 14.266 & 0.0 & Side span \\
\hline M25 & 14.919 & 14.919 & 0.0 & Side span \\
\hline M37 & 13.820 & 13.820 & 0.1 & Center span \\
\hline M49 & 13.172 & 13.172 & 0.0 & Center span \\
\hline M61 & 12.715 & 12.715 & 0.0 & Center span \\
\hline M73 & 12.446 & 12.446 & 0.0 & Center span \\
\hline M85 & 12.361 & 12.361 & 0.0 & Center span \\
\hline M97 & 12.461 & 12.461 & 0.0 & Center span \\
\hline M109 & 12.746 & 12.746 & 0.0 & Center span \\
\hline M121 & 13.219 & 13.219 & 0.0 & Center span \\
\hline M133 & 15.747 & 15.747 & -0.1 & Side span \\
\hline M145 & 14.855 & 14.855 & 0.0 & Side span \\
\hline M157 & 14.223 & 14.223 & 0.0 & Side span \\
\hline M168 & 13.869 & 13.869 & 0.0 & Side span \\
\hline H1 & 1.749 & 1.749 & 0.0 & Side span \\
\hline H13 & 35.551 & 35.551 & 0.0 & Side span \\
\hline $\mathrm{H} 25$ & 93.036 & 93.036 & 0.1 & Center span \\
\hline H36 & 160.851 & 160.850 & -0.5 & Center span \\
\hline H37 & 154.542 & 154.542 & 0.0 & Center span \\
\hline H49 & 89.983 & 89.983 & 0.0 & Center span \\
\hline H61 & 45.349 & 45.349 & 0.0 & Center span \\
\hline H73 & 20.049 & 20.049 & 0.0 & Center span \\
\hline H85 & 13.747 & 13.747 & 0.0 & Center span \\
\hline H97 & 26.360 & 26.360 & -0.1 & Center span \\
\hline H109 & 58.055 & 58.055 & -0.1 & Center span \\
\hline H121 & 109.252 & 109.252 & -0.1 & Center span \\
\hline H131 & 159.640 & 159.640 & 0.5 & Side span \\
\hline H133 & 144.928 & 144.928 & 0.1 & Side span \\
\hline H145 & 71.197 & 71.197 & 0.1 & Side span \\
\hline H157 & 21.685 & 21.685 & 0.1 & Side span \\
\hline H165 & 1.749 & 1.749 & 0.0 & Side span \\
\hline
\end{tabular}

TABLE 9: Maximum internal forces and displacements in the main members of Example 2.

\begin{tabular}{|c|c|c|c|c|}
\hline & SAM & $\mathrm{ULM}(\mathrm{S})$ & G.TCUD [8] & $\mathrm{ULM}(\mathrm{G})[8]$ \\
\hline Horizontal tension component of the main cable $(\mathrm{kN})$ & $569,634.8$ & $569,634.3$ & $569,639.5$ & $569,639.8$ \\
\hline Max. tension of the hanger cable $(\mathrm{kN})$ & $7,015.7$ & $7,015.7$ & $7,015.7$ & $7,015.7$ \\
\hline Max. compressive force of the tower $(\mathrm{kN})$ & $608,372.2$ & $608,793.6$ & $-608,818.5$ & $-608,818.8$ \\
\hline Max. positive moment of the main girder $(\mathrm{kN} \cdot \mathrm{m})$ & $8,628.2$ & $6,199.8$ & $6,199.3$ & $6,200.7$ \\
\hline Max. negative moment of the main girder $(\mathrm{kN} \cdot \mathrm{m})$ & $-6,646.6$ & $-9,074.5$ & 9075.6 & $-9,077.3$ \\
\hline Unstrained length of the entire main cable $(\mathrm{m})$ & $2,287.5$ & $2,287.5$ & $2,287.5$ & $2,287.5$ \\
\hline Max. bending moment of the tower $(\mathrm{kN} \cdot \mathrm{m})$ & 0.0 & 23.7 & 0.0 & 1.1 \\
\hline Horizontal displacement at the top of the tower $(\mathrm{mm})$ & 0.0 & 0.2 & 0.0 & 0.0 \\
\hline Vertical displacement at the top of the tower ( $\mathrm{mm})$ & 0.0 & 0.3 & 0.0 & 0.0 \\
\hline Axial shortening of the whole main girder (mm) & 0.0 & 0.0 & 0.0 & 0.0 \\
\hline Max. vertical displacement of the main girder $(\mathrm{mm})$ & 0.0 & 0.0 & 0.0 & 0.0 \\
\hline
\end{tabular}

In the case of self-anchored suspension bridges having an upward fabrication camber convex, an initial solution obtained by an analytical method can lead to globally very large negative bending moments in the main girder due to the combined effect of the camber and the compressive force transmitted from the main cable if the horizontal tension component is not updated iteratively. To eliminate the negative moments induced in the main girder due to $P-\Delta$ effect in self-anchored suspension bridges, the hanger tension should be suitably decreased, which results in increasing the vertical profile of the main cable. This can be achieved by SAM, which adopts the continuous girder model subjected 


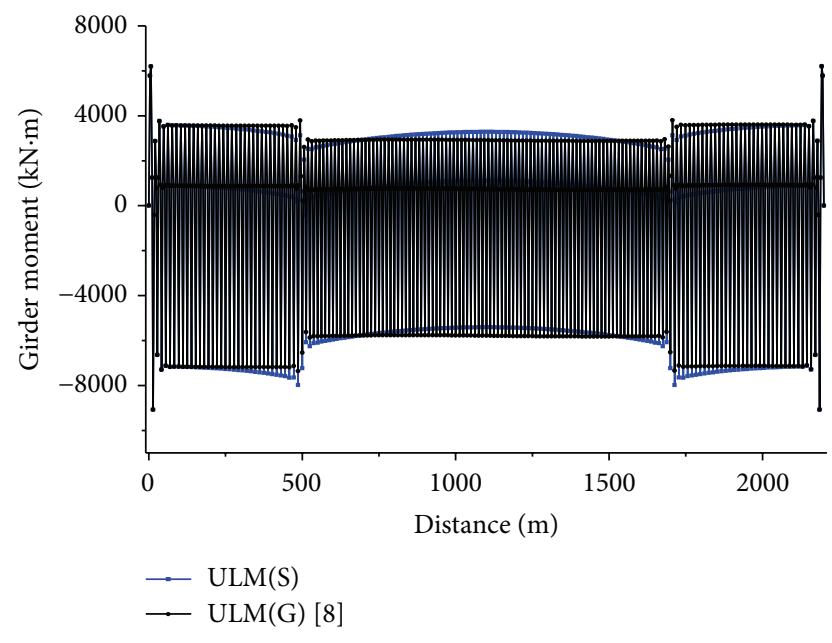

FIGURE 11: Bending moment diagram of the main girder in the selfanchored suspension bridge.

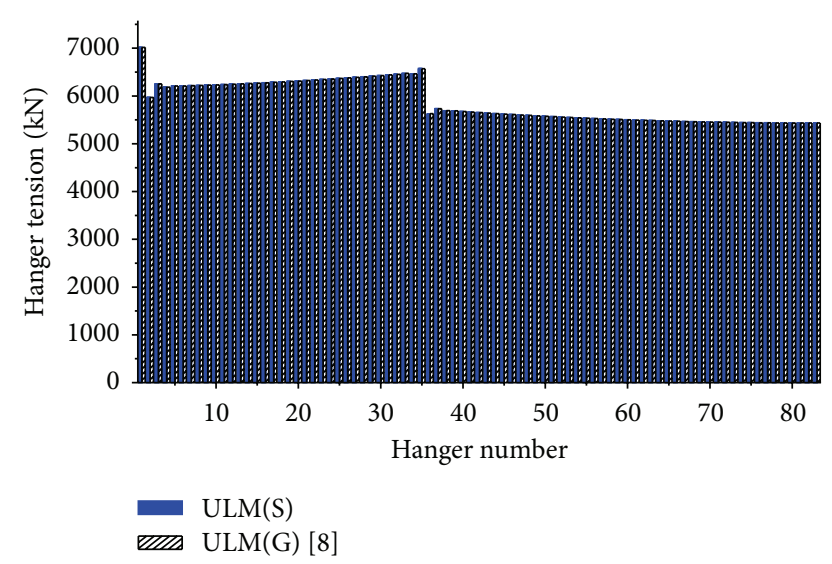

FIGURE 12: Distribution of hanger tensions in the self-anchored suspension bridge.

to both its self-weight and the updated horizontal tension of the main cable through an iteration process.

Consequently, SAM can provide the optimized initial state of the self-anchored suspension bridge because not only is the initial solution obtained by $\operatorname{ULM}(S)$ based on SAM in full agreement with that by SAM, but also it leads to only minimized bending moments of the main girder, eliminating the bending moments of towers, and the initial shape conforms very well to the target configuration.

\section{Disclosure}

The revised paper has been checked by an English-writing expert.

\section{Conflict of Interests}

The authors declare that there is no conflict of interests regarding the publication of this paper.

\section{References}

[1] R. Karoumi, "Some modeling aspects in the nonlinear finite element analysis of cable supported bridges," Computers and Structures, vol. 71, no. 4, pp. 397-412, 1999.

[2] H.-K. Kim, M.-J. Lee, and S.-P. Chang, "Nonlinear shapefinding analysis of a self-anchored suspension bridge," Engineering Structures, vol. 24, no. 12, pp. 1547-1559, 2002.

[3] K. Zhang and J. Lei, "Analysis of cable curve and determination of finished state of self-anchored suspension bridge," in Proceedings of the 2nd International Conference on Mechanic Automation and Control Engineering (MACE '11), pp. 1935-1938, Hohhot, China, July 2011.

[4] D. W. Chen, F. T. K. Au, L. G. Tham, and P. K. K. Lee, "Determination of initial cable forces in prestressed concrete cable-stayed bridges for given design deck profiles using the force equilibrium method," Computers and Structures, vol. 74, no. 1, pp. 1-9, 2000.

[5] S. Wang, Z. Zhou, Y. Gao, and Y. Huang, "Analytical calculation method for the preliminary analysis of self-anchored suspension bridges," Mathematical Problems in Engineering, vol. 2015, Article ID 918649, 12 pages, 2015.

[6] K.-S. Kim and H. S. Lee, "Analysis of target configurations under dead loads for cable-supported bridges," Computers and Structures, vol. 79, no. 29-30, pp. 2681-2692, 2001.

[7] H.-K. Kim and M.-Y. Kim, "Efficient combination of a TCUD method and an initial force method for determining initial shapes of cable-supported bridges," International Journal of Steel Structures, vol. 12, no. 2, pp. 157-174, 2012.

[8] M.-R. Jung, D.-J. Min, and M.-Y. Kim, "Nonlinear analysis methods based on the unstrained element length for determining initial shaping of suspension bridges under dead loads," Computers and Structures, vol. 128, pp. 272-285, 2013.

[9] M. M. Hassan, "Optimization of stay cables in cable-stayed bridges using finite element, genetic algorithm, and B-spline combined technique," Engineering Structures, vol. 49, pp. 643654, 2013.

[10] P. Lu, J. Chen, J. Zhong, and P. Lu, “Optimization analysis model of self-anchored suspension bridge," Mathematical Problems in Engineering, vol. 2014, Article ID 403962, 8 pages, 2014.

[11] M. A. Crisfield, Non-Linear Finite Element Analysis of Solids and Structures, vol. 1, Wiley, Chichester, UK, 1997.

[12] T.-N. Le, J.-M. Battini, and M. Hjiaj, "Efficient formulation for dynamics of corotational 2D beams," Computational Mechanics, vol. 48 , no. 2, pp. 153-161, 2011. 


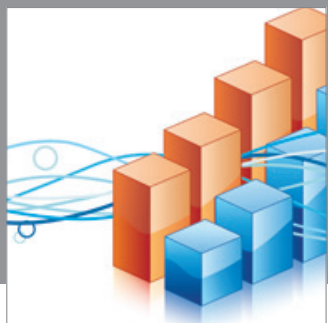

Advances in

Operations Research

mansans

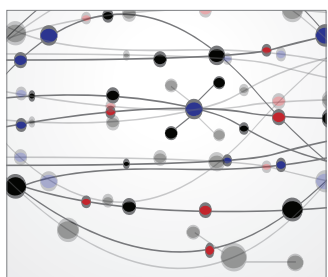

The Scientific World Journal
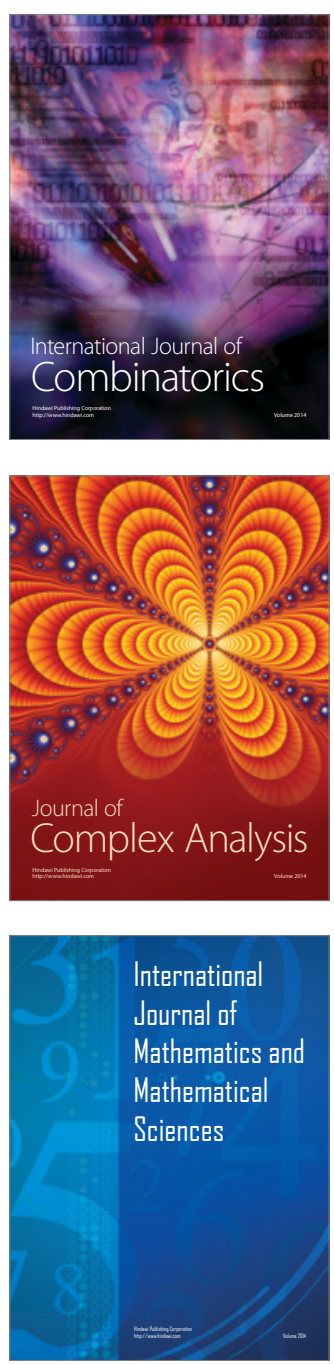
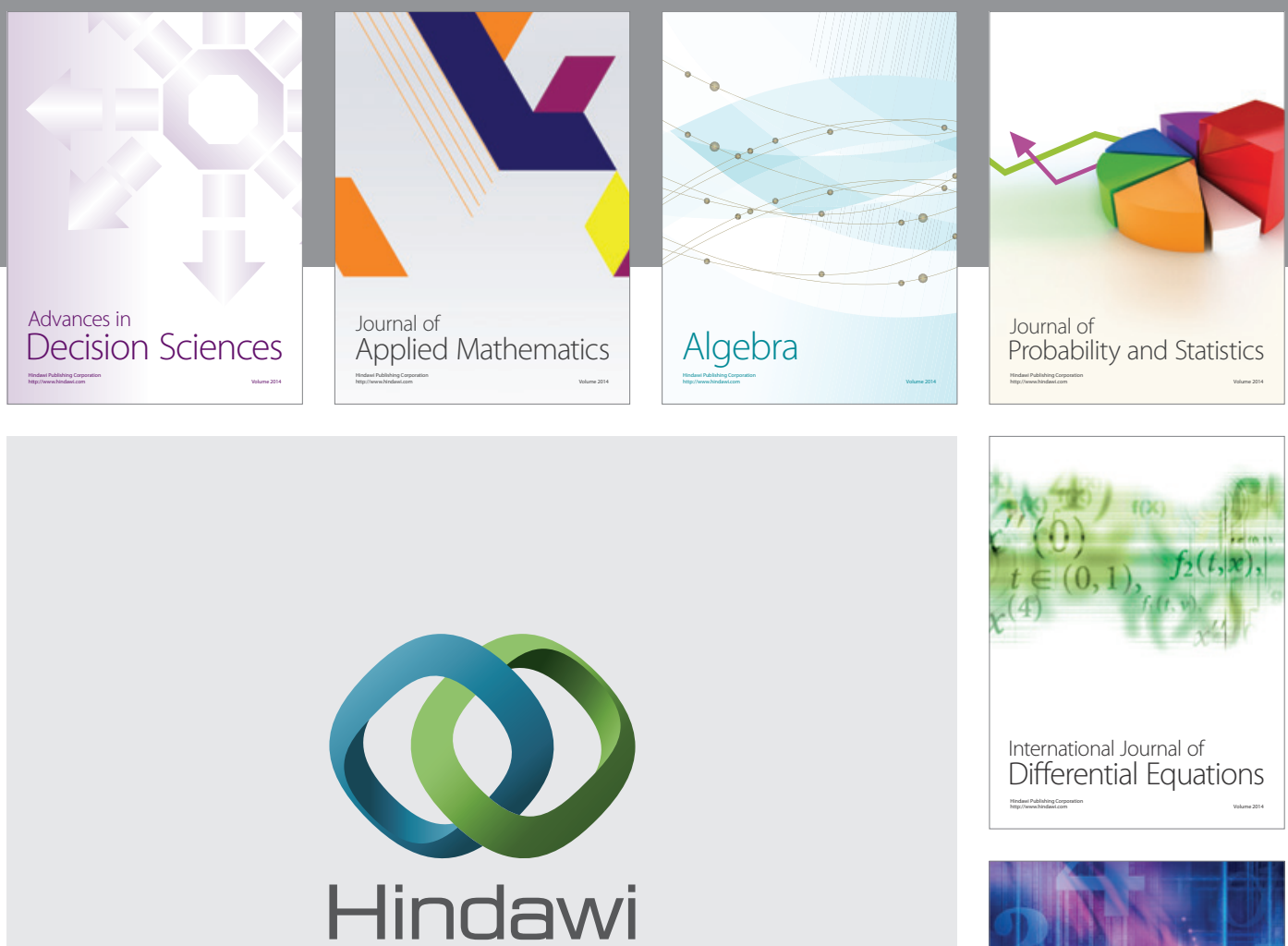

Submit your manuscripts at http://www.hindawi.com
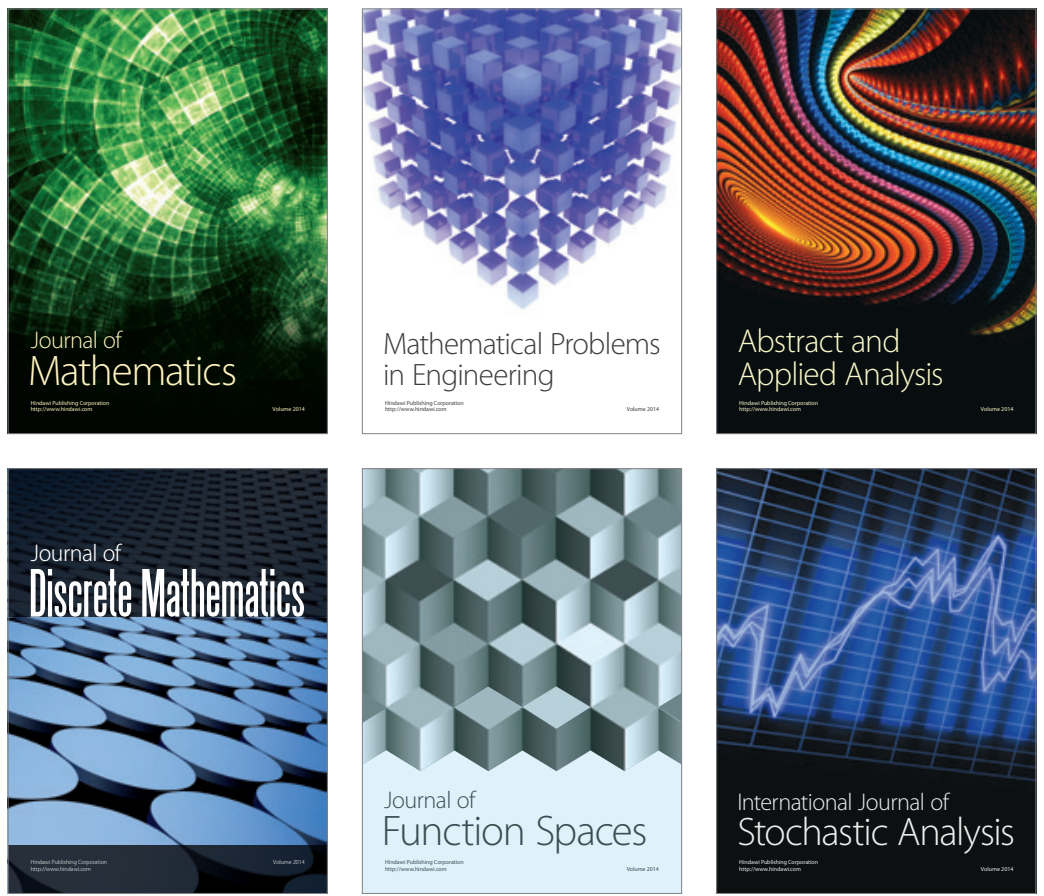

Journal of

Function Spaces

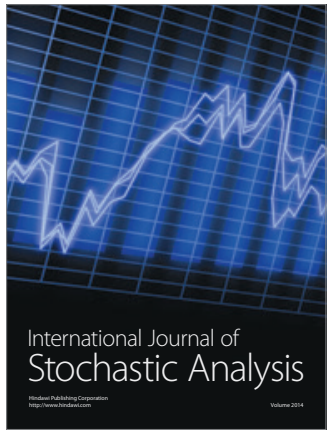

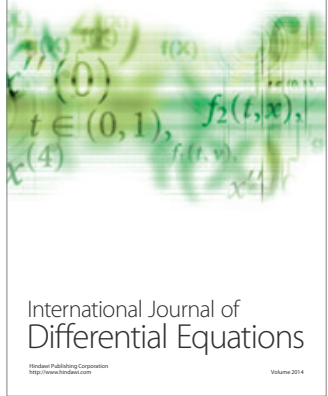
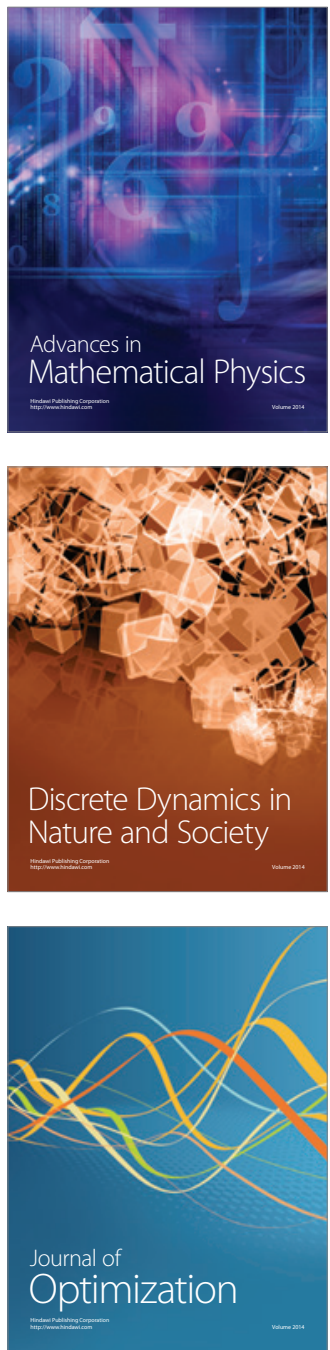